\title{
Not so good old summertime
}

\author{
LE Nicolle MD FRCP, Editor-in-Chief
}

$\mathrm{V}$ isions of another glorious Canadian summer shimmer before us - a world of light and warmth after a cold, dark season. Cottages, lakes, barbecues and long, warm evenings beckon. There will be hikes through the bush, socializing over hamburgers, drinks on the deck at sunset, and sand and swimming at the beach.

What is wrong with this picture? It's the persistent drone of messages alerting us to an ever-increasing danger with summertime and summer pursuits. There is no need to consider noninfectious problems such as skin cancer or off-road vehicle accidents; there is sufficient alarm considering only the infectious diseases. Bird watchers now wonder if the glory of the spring migration heralds an importation of avian influenza. As you hike or canoe through the great Canadian wilderness, watch for ticks and their burden of Borrelia burgdorferi. Is the coliform count in your lake acceptable to the local health department? And beware that Trojan horse on a beautiful summer evening the mosquito carrying West Nile virus. The only potential positive message, in a negative way, is that Escherichia coli 0157:H7 is no longer just a problem of the summer barbecue; it now arrives all year round, on spinach, alfalfa sprouts and other foods promoted for healthy eating.

To what do we attribute this summer largesse of 'emerging' infections? The usual suspects - human behaviour, agricultural practice, global trade and global warming - all play roles. Dissemination of avian influenza is facilitated through agricultural practices both in developing and developed countries, although the influenza virus and reassortment of influenza viruses is part of the long view of human history. Lyme disease may have become more prominent with increased exposure of humans to animals and habitats, where tick vectors occur, and, at least in Canada, these ticks may also be expanding their habitat with climate change. The determinants of coliform levels in the water of beaches are multifactorial and are not fully understood. However, current farming practices play some role, and straightforward issues such as inappropriate sewage disposal also contribute. Perhaps global warming is also at play here. West Nile virus was, of course, introduced to North America through either travel or trade, with the extent of each year's outbreak in Canada dependent on climate conditions. Finally, enterotoxigenic E coli is invariably traced to herds, which, if not contaminating hamburger meat directly, are contaminating ground water and vegetables or fruits in nearby fields. Improved diagnostic approaches, together with more effective surveillance and information dissemination, increase the recognition of problems that may not have been previously apparent.

As the infectious terrors of summer mount, diverse and not necessarily cohesive recommendations assail us with advice to keep us infection-free. Make sure the burgers are well cooked. Don't swim in your favourite lake or beach when warning notices are posted. Cover your skin in the heat of summer so the mosquitoes won't bite and the ticks won't attach. Wear gloves when you pick up dead birds. Apply bug spray. Don't stay outside in the evening - that's when Culex tarsalis mosquitoes bite. These messages are a long way from the pure pleasure of warmth, light and freedom - thoughts of summer that a long, Canadian winter should bring. Is the choice only between cowering indoors with a daily workout on the treadmill while clutching our vitamin D tablets or stepping outside in full survival gear to challenge the gauntlet of ever-expanding infection risks?

Monitoring the occurrence, impact and risk associations of these emerging summer blights is important to gain perspective in assessing the balance between safety and fun. Aspects of two of these summer issues are addressed in this issue of the Journal. The guidelines for the laboratory diagnosis of Lyme disease (pages 145 to 148), developed by the Canadian Public Health Laboratory Network, are based on current knowledge and appropriate laboratory practice. These will be helpful for Canadian clinicians and laboratorians. They will also assist in the management of patients diagnosed with 'Lyme disease' through serological testing by largely American, private laboratories, often using nonstandardized tests. The second article (pages 153 to 157), prepared by Lévesque and Gauvin, provides a summary and critical evaluation of the current science relevant to interpretations of levels of coliforms and other bacteria appropriate for safe recreational use in natural waters. The recommendations and conclusions will not encourage water activities, but they will help to focus attention on the issue and, perhaps, move us forward in addressing whatever part of the problem is amenable to intervention. Canada already has comprehensive and effective national surveillance for $E$ coli 0157:H7 and West Nile virus infection, with each new outbreak or season providing new knowledge to refine our understanding of risk. Worldwide, the capacity to track influenza viruses, including avian influenza, is remarkable. But none of this puts the fun back into summer.

What are we to do? Public health departments have an obligation to warn of real or potential dangers from communicable diseases, and to determine how these may be mitigated. But we should also acknowledge some positive messages. Lyme disease is not only effectively diagnosed, but also effectively treated. An evaluation from a public health perspective of devices marketed for mosquito removal would be useful, so we can relax outside on a summer evening. And the screen remains a wonderful invention. We need to hear about progress being made toward understanding and addressing the risks to food safety potentially attributable to current agricultural practices. Climate concerns now have everyone's attention and, hopefully, some progress will be achieved in this complex area. The pleasures of summer should not be burdened by insecurity about ever-increasing infections. A balance between the negative and the positive messages should be sought. And, yes, the hamburgers must still be well cooked. 


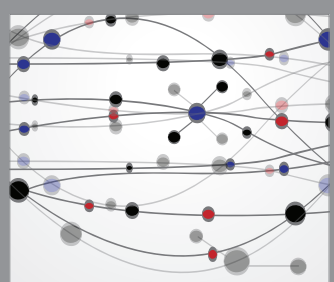

The Scientific World Journal
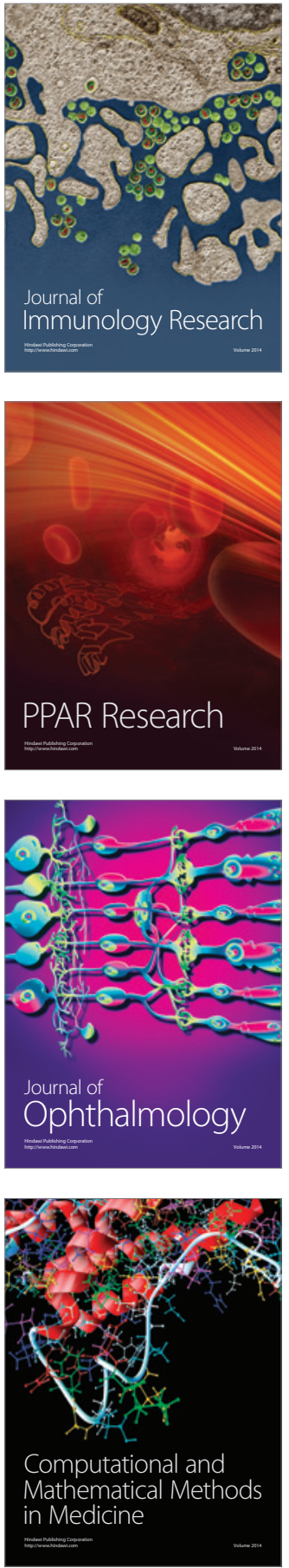

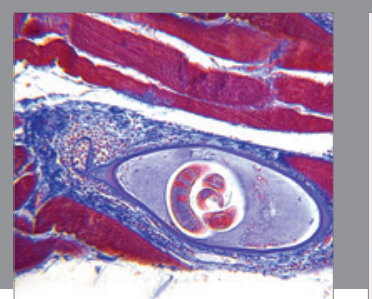

Gastroenterology Research and Practice

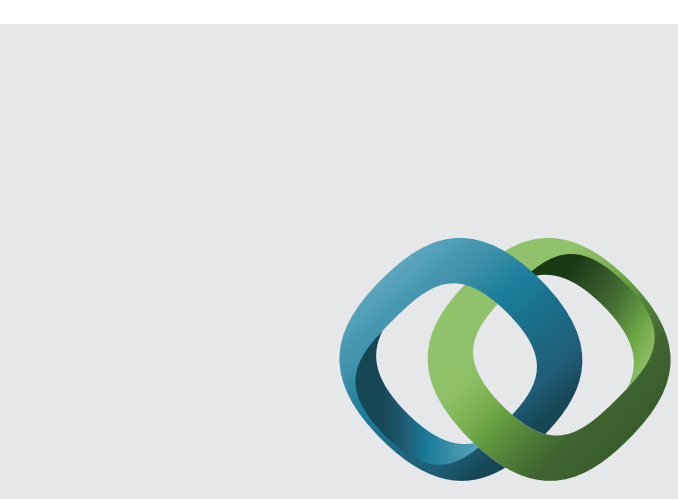

\section{Hindawi}

Submit your manuscripts at

http://www.hindawi.com
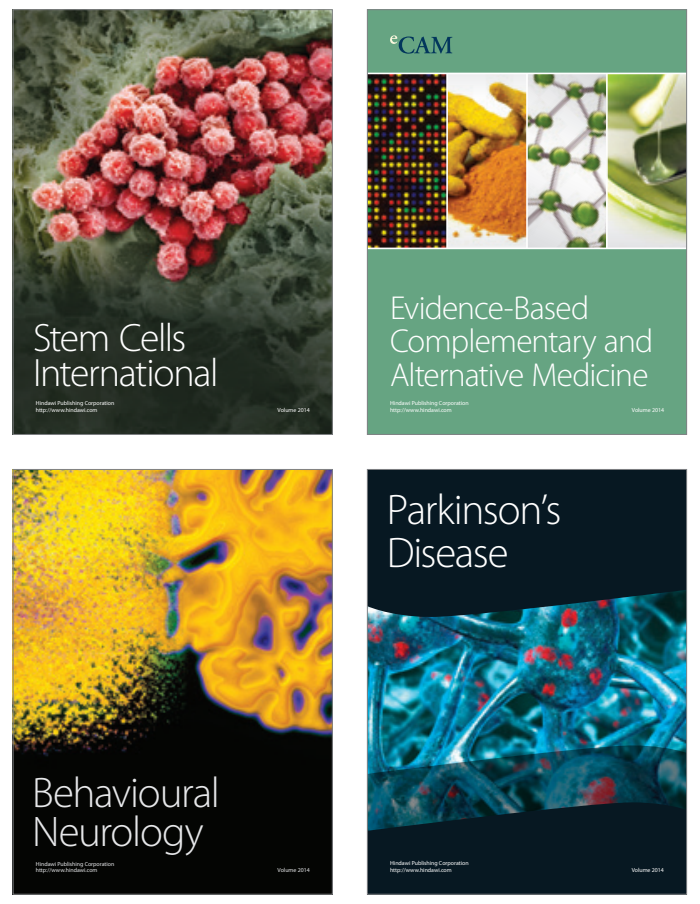
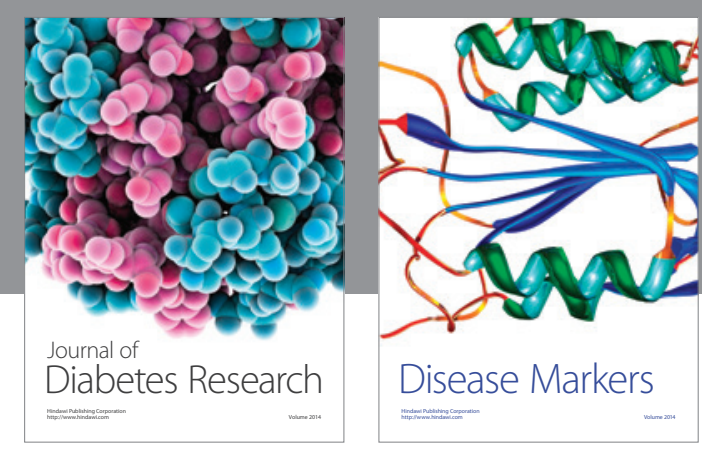

Disease Markers
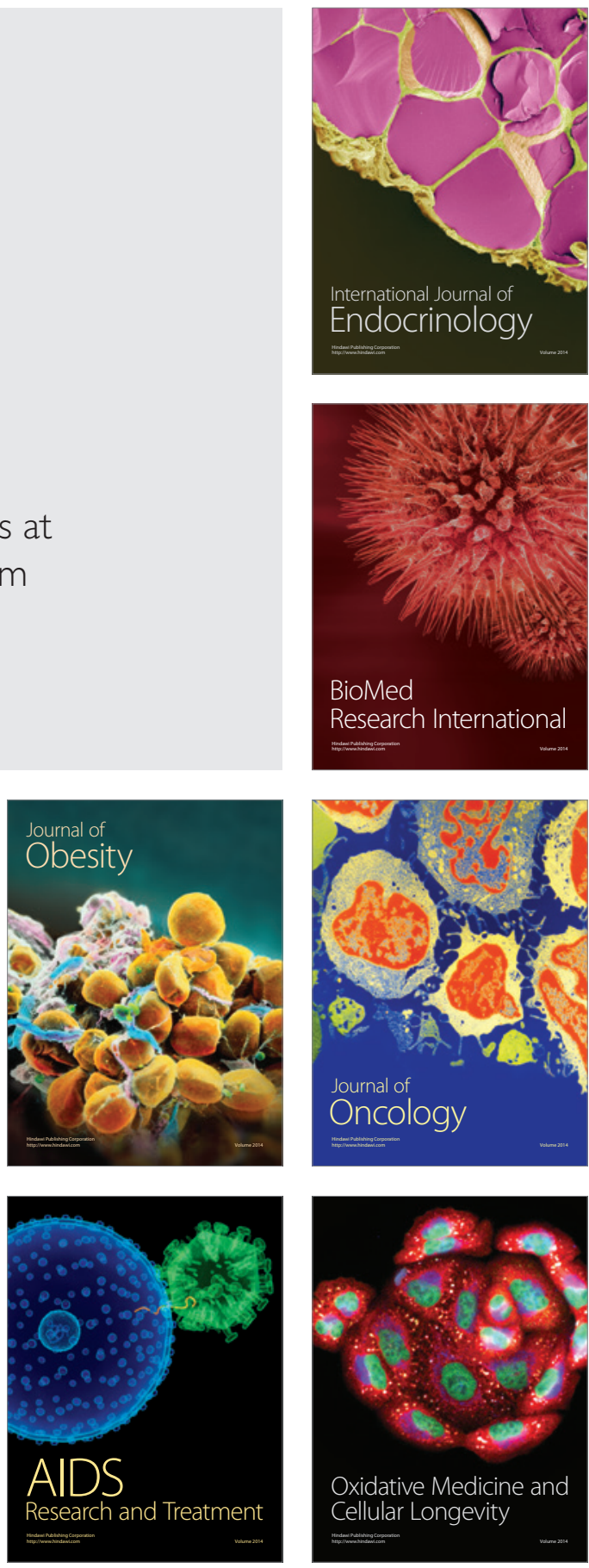